\title{
Bilateral Pneumothoraces after Transtracheal High Frequency Jet Ventilation during Emergency Tracheostomy
}

\author{
Bruno J AWAN and J.H. LEE
}

(Key words: cardiac arrest, HFJV bilateral pneumothoraces)

\begin{abstract}
In cardiac arrest, the first steps of cardiopulmonary resuscitation (CPR) are to keep airway patent and support breathing. Sometimes airway management is difficult with mask or endotracheal intubation. In such life treatening situation percutaneous transtracheal high frequency jet ventilation (THFJV) has been used successfully ${ }^{1,2}$. A case of successful CPR with such method but complicated by bilateral pneumothoraces (BPT), pneumomediastinum (PM), Pneumoretroperitonium (PRP) and subcutaneous emphysema (SE) is presented.
\end{abstract}

\section{Case Report}

A 21-year-old male, $48 \mathrm{~kg}$ with severe left temporomandibular joint (TMJ) ankylosis and complete trismum was brought to the operating room without premedication for releas of ankylosis. Past history revealed an abnormal facial development with TMJ ankylosis and micrognathia. The patient could not open his mouth at all and took only liquid fluid since childhood. For the last 10 years he has been suffering from sleep apnea

Department of Anesthesiology, Chang Gung Memorial Hospital, Kaohsiung, Taiwan, ROC

Address reprint requests to Dr. Jawan: Department of Anesthesiology, Chang Gung Memorial Hospital, 123, Ta-Pei Rd., Niao Sung Hsiang, Kaohsiung Hsien, Taiwan, ROC
\& narcolepsy. He even fell asleep during eating or bathing. His preoperative data showed arterial blood gases of $\mathrm{pH}$ : 7.30, $\mathrm{Pa}_{\mathrm{CO}_{2}}$ : 74 torr and $\mathrm{PaO}_{2}: 50$ torr. Pulmonary function test showed obstructive ventilatory impairment. Chest X-ray showed some infiltration of both lower lungs without bullae. His hemoglobin was $12.9 \mathrm{Gm}$, with hematocrit: $\mathbf{5 0 . 7 \%} \&$ WBC: 9900 . Electrolytes and EKG were within normal limits.

Awake blind nasal intubation under topical and transtracheal anesthesia was tried first. After $\mathbf{4 0} \mathrm{min}$ the intubation was still not possible. The plan was then switched to tracheostomy under local anesthesia. A mid-tracheostomy was performed. During excision of the tracheal ring the patient suddenly developed apnea and cardiac standstill. A THFJV was immediately started through the tracheal incision with a 14 gauge Medicath needle connected to the IDC (Instrument Development Corporation) VS 600 ventilator which was on standby. A driving pressure of 26 psi and $150 / \mathrm{min}$ frequency with inspiration/expiration ratio of 0.4 were used. After $1 \mathrm{mg}$ atropine, $40 \mathrm{ml}$ $7 \%$ sodium bicarbonate i.v. and closed chest cardiac massage, sinus tachycardia with 120 beats. $\mathrm{min}^{-1}$ and BP of $160 / 90 \mathrm{mmHg}$ were restored. The im- 
Table 1. ABG changes during procedure

\begin{tabular}{|c|c|c|c|c|c|c|}
\hline & & 1 & 2 & 3 & 4 & 5 \\
\hline Time & Preoperative & 11.20 & 11.25 & 11.27 & 12.15 & 13.00 \\
\hline $\mathrm{pH}$ & 7.30 & 7.07 & 7.03 & 7.07 & 7.29 & 7.43 \\
\hline $\mathrm{Pa}_{\mathrm{CO}_{2}}(\mathrm{mmHg})$ & 74 & 151 & 191 & 146 & 75 & 47 \\
\hline $\mathrm{Pa}_{\mathrm{O}_{2}}(\mathrm{mmHg})$ & 50 & 78 & 57 & 72 & 105 & 432 \\
\hline $\mathrm{H}_{\mathrm{CO}_{3}}$ & 37 & 43 & 49 & 42 & 38 & 30 \\
\hline $\mathrm{BE}$ & 6 & 6.5 & 10.9 & 5.5 & 6.2 & 6.0 \\
\hline $\mathrm{Sa}_{\mathrm{O}_{2}}(\%)$ & 84 & 88 & 84 & 86 & 99 & 99.9 \\
\hline
\end{tabular}

1: immediately after cardiac arrest

2: during tracheostomy, ventilation supported with HFJV

3: after insertion of tracheostomy tube, ventilation supported with IPPV

4: waiting for X-ray, ventilation supported with IPPV

5: after insertion of chest tubes, ventilation supported with IPPV

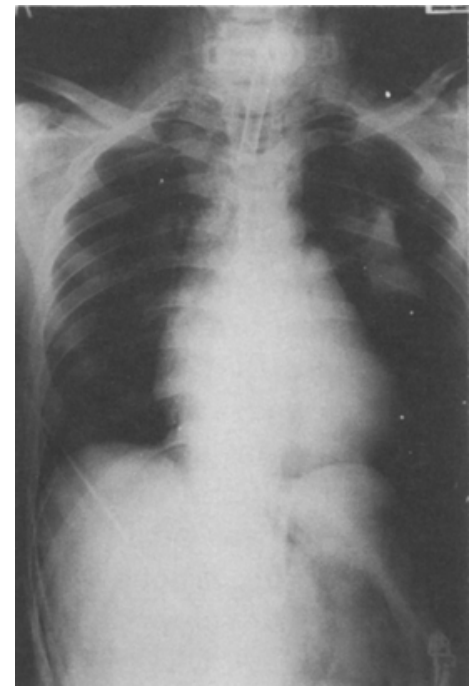

Fig. 1. Chest X-ray shows bilateral pneumothoraces with collaps of the left lung more than right lung, pneumomediastinum, pneumoretroperitoneum and subcutaneous emphysema over the face, neck and the chest wall.

mediate arterial blood gases analysis (table 1) showed a marked respiratory acidosis. Because of severe hypercapnia, the ventilation was supported with THFJV during tracheostomy. The Medicath needle of the high frequency jet ventilation (HFJV) had to be with- drawn several times into the top of the tracheal incision in the peritracheal area for surgical exposure. After completion of the tracheostomy, general anesthesia was started with 0.2 $\mathrm{mg}$ of Fentanyl and $100 \mathrm{mg}$ penthothal given IV and Isoflurane. At that time severe subcutaneous emphysema (SE) over the face, neck and chest were observed. Breathsounds in both lungs were decreased, and pneumothorax was suspected. Chest $\mathrm{X}$-ray revealed BPT, PM, PRP and SE (fig. 1). After insertion of bilateral chest tubes the ABG's were normal (table 1) with blood pressure of $120 / 80$ and heart rate of $80 / \mathrm{min}$. The operation was cancelled and the patient was sent to the intensive care unit. He recoverd from the incident uneventfully and the operation was performed successfully three weeks later.

\section{Discussion}

Incidence of pneumothorax after tracheostomy were reported with less than $1 \%^{3}$ in adult and $4.3 \%$ in children $^{4}$. Bilateral pneumothoraces was even rarely reported $^{5}$. Tracheostomy may cause pneumothorax in two different ways. First is direct 
injury of dome of the pleura. Second is leakage of air from the tracheostomy to the surrounding tissues, which is commonly seen as subcutaneous emphysema ${ }^{6,7,8}$. If the air continues to accumulate and dissects the fascial planes of the neck into the mediastinum, it may lead to pneumomediastinum and pneumothorax ${ }^{6,7,8}$. It happens rarely and usually is associated with excessive negative airway pressure that developed during obstructed or labored respiration ${ }^{6,7,8}$ and should be a. slow process. In our case no bucking or obstructed airway during tracheostomy was seen and the bilateral pneumothoraces occurred very rapidly. The mechanism should be other than simple air leakage. Direct injury of the dome of the pleura which normally causes one-sided pneumothorax was also unlikely since a midtracheostomy was performed. Closed chest cardiac massage may cause pneumothorax if the pleura is injured by rib fracture. Chest X-ray showed no rib fracture in our patient. One of the advantages of HFJV is use of small tidal volume and high frequency, which creates low airway pressure and decreases the incidence of barotrauma ${ }^{9}$. Although the patient had a poor pulmonary function test, there was no bullae or emphysematous change in his lungs. There was no evidence of tension pneumothoraces. This indicates that the entry port of the air in the pleural cavity was not in the lung parenchyma, but somewhere else, and the air seemed to have entered the mediastinum very rapidly with pressure high enough to rupture both pleuras and dissect the fascias around the great vessels of the mediastinum.

After successful CPR with HFJV jetting the oxygen through the tracheal incision, the $\mathrm{PaCO}_{2}$ was still 151 torr and $\mathrm{PaO}_{2} 78$ torro. Because of $\mathrm{CO}_{2}$ retention, the ventilation was supported by HFJV during further tracheostomy.
The needle of the HFJV had to be withdrawn several times into the peritracheal area before completing the tracheostomy. We feel the most likely cause of the event was blowing of oxygen and air from the HFJV into the peritracheal area. The HFJV needle might have been occasionally placed near or inside the fascial planes during tracheostomy. Under normal condition and without positive pressure, and open fascial planes in tracheostomy will not cause pneumothorax ${ }^{7,8}$. But with HFJV, the pressure would be sufficient enough to blow oxygen and air into the mediastinum through the fascial planes and rupture the parietal layer of pleura of both lungs if the needle was in or near the open fascial planes. The air could further dissect around the great vessels of the mediastinum into retroperitoneum forming penumoretroperitonium.

When using HFJV for tracheastomy, we recommend that the jetting cannula should be firmly fixed in the tracheal lumen. Great care should be taken when moving cannula inside the tracheal incision since removal of the cannule under continued HFJV may blow air into the fascial planes with possible development of complications described above.

(Received Jul. 23, 1991, accepted for publication Dec. 27, 1991)

\section{References}

1. Klain M, Keszler H, Brader E: High frequency jet ventilation in CPR. Crit Care Med 9:421-422, 1981

2. Brader $E$, Klain $M$, Safar $P$, et al: High frequency jet ventilation versus IPPV in cardiopulmonary resuscitation for asphyxia in dogs. Crit Care Med 9:162, 1981

3. James W. Meada: Tracheostomy - Its complications and there management. N Engl J Med 265:519-522, 1961

4. Tucker JA, Silberman, HD: Tracheostomy in pediatrics. Ann Otol, Rhinol Laryngol 81:818-824, 1972 
5. Parikh D: A case of bilateral pneumothorax after tracheostomy. J Laryngol Otol 79:457-461, 1965

6. Denlimger JK: Pneumothorax in Orkin, F.K. and Cooperman, L.H.: Complications in Anesthesiology. Lippincott 1982

7. Martin JT, Patrick RT: Pneumotho- rax, its significance to the anesthesiologist. Anesth Analg 39:420, 1960

8. Herman PG: Iatrogenic thoracic complications. Springer-Verlag, New York, Heidelberg, Berlin, 1983

9. Sjostrand U: High frequency positive pressure ventilation: A review. CritCare Med 8:345-364, 1980 